\title{
Expression and Antibacterial Activity of a Bombus ignitus Apidaecin in Baculovirus-Infected Insect Cells
}

\author{
Kwang Sik Lee ${ }^{1}$, Yeon Ho Je ${ }^{2}$, Byung Rae Jin ${ }^{1}$, and Hung Dae Sohn ${ }^{1, *}$ \\ ${ }^{1}$ College of Natural Resources and Life Science, Dong-A University, Busan 604-714, Republic of Korea \\ ${ }^{2}$ Department of Agricultural Biotechnology, College of Agriculture \& Life Sciences, Seoul 151-742, Republic of Korea
}

(Received 26 January 2012; Accepted 25 February 2012)

The apidaecins are highly active against Gram-negative bacteria. Here, we show the expression and antibacterial activity of the bumblebee, Bombus ignitus, apidaecin. We PCR-amplified 51 bp of the active domain sequence of the $B$. ignitus apidaecin gene and expressed the recombinant $B$. ignitus apidaecin active domain in baculovirus-infected insect cells. The recombinant $B$. ignitus apidaecin active domain shows bactericidal activity against Gram-negative bacteria, including Pseudomonas tolaasii, a serious pathogen in cultivated mushrooms, but not Gram-positive bacteria. This result suggests that the active domain of the $B$. ignitus apidaecin is a potential antibacterial agent for the control of bacterial brown blotch diseases.

Key words: Antibacterial activity, Apidaecin, Bumblebee, Insect cells, Mushroom, Pseudomonas tolaasii

\section{Introduction}

Bacterial brown blotch diseases of the button (Agaricus bisporus) and oyster (Pleurotus ostreatus) mushrooms are caused by Pseudomonas tolaasii (Paine, 1919). P. tolaasii is a serious pathogen in cultivated mushrooms; it is endemic in mushroom farms and results in significant reductions in mushroom yield and quality (Prashanth et al., 2011). However, the control of bacterial diseases in cultivated mushrooms, such as Agaricus and Pleurotus spp., has been limited because suitable control measures and bactericides are lacking (Gill, 1995). Hence, novel

\footnotetext{
*To whom the correspondence addressed

College of Natural Resources and Life Science, Dong-A University, Busan 604-714, Republic of Korea.

E-mail: hdsohn@dau.ac.kr
}

and alternative control methods are needed. Currently, bacterial brown blotch diseases are controlled in mushroom cultivation houses by fumigation and by sterilizing water. A recent study has shown that the introduction of a Bacillus thuringiensis crystal protein into an antimicrobial Bacillus brevis strain has dual insecticidal and antibacterial activities, protecting against mosquito larvae and $P$. tolaasii, respectively (Roh et al., 2010).

Four genes encoding antibacterial peptides (apidaecin, hymenoptaecin, abaecin, and defensin) were cloned from the bumblebee Bombus ignitus (Choi et al., 2008). Among these antibacterial peptides, the apidaecins are highly active against Gram-negative bacteria (Casteels et al., 1989; Li et al., 2006). In this study, we evaluated the activity of the $B$. ignitus apidaecin against a Gram-negative bacterium, $P$. tolaasii, and report on the expression and antibacterial activity of the recombinant $B$. ignitus apidaecin. We PCR-amplified and expressed the active domain sequence of the $B$. ignitus apidaecin gene in baculovirus-infected insect cells. Additionally, we assayed the antibacterial activity of the recombinant $B$. ignitus apidaecin active domain against three Gram-negative bacteria and four Gram-positive bacteria.

Materials and Methods

\section{Gene cloning and sequence analysis}

The $B$. ignitus apidaecin active domain was PCR-amplified using a primer set designed from the $B$. ignitus apidaecin gene sequence (Choi et al., 2008): the forward primer (321329), 5'-GATCCAGAAGAATTCATGGCCAACCGA-3' (EcoRI site was introduced) and the reverse primer (363371), 5'-CAGCTTCGCCTCGAGAAGACGCGG-3' (Xho I site was introduced). PCR was performed according to a defined protocol: $94^{\circ} \mathrm{C}$ for $2 \mathrm{~min}, 30$ cycles of amplification $\left(94^{\circ} \mathrm{C}\right.$ for $30 \mathrm{sec} ; 55^{\circ} \mathrm{C}$ for $30 \mathrm{sec}$; and $72^{\circ} \mathrm{C}$ for 30 sec) and $72^{\circ} \mathrm{C}$ for $5 \mathrm{~min}$. The nucleotide sequences of PCR products were determined using a BigDye termina- 
tor cycle sequencing kit and an automated DNA sequencer (Perkin-Elmer Applied Biosystems, Foster City, CA).

\section{Expression of the recombinant peptide}

A baculovirus expression vector system, based on the Autographa californica nucleopolyhedrovirus (AcNPV) and the Sf9 insect cell line (Je et al., 2001), was used for the production of the recombinant $B$. ignitus apidaecin active domain. The $51 \mathrm{bp}$ B. ignitus apidaecin active domain was inserted into the $\mathrm{pBAC1}$ vector (Clontech, Palo Alto, CA) to generate an expression vector in which the expression of the recombinant protein is under the control of the AcNPV polyhedrin promoter. Recombinant baculoviruses were propagated in $\mathrm{Sf} 9$ cells cultured in TC100 medium (Gibco BRL, Gaithersburg, MD) at $27^{\circ} \mathrm{C}$. Recombinant proteins were purified using a HisTrap column (Amersham Biosciences, Arlington Heights, IL). Protein concentrations were determined using the BioRad Protein Assay Kit.

\section{Antibody preparation and Western blot analysis}

The purified recombinant $B$. ignitus apidaecin active domain $(20 \mu \mathrm{g})$ was mixed with an equal volume $(200 \mu \mathrm{l})$ of Freund's complete adjuvant (Sigma Chemical Co., St. Louis, MO) and injected into BALB/c mice (Semtaco Bio Korea Co., Korea). Two subsequent injections were administered using antigens mixed with equal volumes of Freund's incomplete adjuvant $(200 \mu \mathrm{l})$ at oneweek intervals, beginning one week after the first injection. Blood was collected three days after the last injection (antigen only) and centrifuged at $10,000 \times \mathrm{g}$ for 10 min after clotting at $4^{\circ} \mathrm{C}$ overnight. The supernatant antibodies were stored at $-70^{\circ} \mathrm{C}$ until use. Western blot analysis was performed using an enhanced chemiluminescence (ECL) western blotting analysis system (Amersham Biosciences, Piscataway, NJ). Protein samples were mixed with sample buffer, boiled for $5 \mathrm{~min}$, and loaded on a $15 \%$ SDS-polyacrylamide gel electrophoresis (SDSPAGE). Following electrophoresis, the proteins were blotted onto a sheet of nitrocellulose transfer membrane (Schleicher \& Schuell, Dassel, Germany). After blotting, the membrane was blocked by incubation in a $1 \%$ bovine serum albumin (BSA) solution, incubated with an antiserum solution $(1: 1,000 \mathrm{v} / \mathrm{v})$ at room temperature for $1 \mathrm{hr}$, and washed in TBST (10 mM Tris-HCl, $\mathrm{pH} 8.0$, $100 \mathrm{mM} \mathrm{NaCl}, 0.05 \%$ (w/v) Tween 20). The membrane was then incubated with horseradish peroxidase-conjugated anti-mouse IgG diluted 1:5,000 (v/v). After repeated washing, the membrane was incubated with ECL detection reagents (Amersham Biosciences) and exposed to film.

\section{Antibacterial assay}

The antibacterial activity of the recombinant B. ignitus apidaecin active domain was assayed, as described previously (Choo et al., 2010). Purified recombinant B. ignitus apidaecin active domain was tested for antibacterial activity against three Gram-negative bacteria (Escherichia coli, $P$. tolaasii, and $P$. aeruginosa) and four Gram-positive bacteria (B. thuringiensis, B. megaterium, B. subtilis, and $B$. cereus). Inocula (200 $\mu$ l of a culture containing 1.5 $\times 10^{6} \mathrm{cfu} / \mathrm{ml}$ ) of $P$. tolaasii and B. thuringiensis $656-3$ were spread onto sterile Luria-Bertani (LB) agar plates, and the surface of the plates was allowed to dry for approximately $5 \mathrm{~min}$. A $20-\mu \mathrm{l}$ aliquot of recombinant $B$. ignitus apidaecin active domain (40 mg) was then dropped onto LB agar plates that had been inoculated with bacteria. An equivalent volume $(20 \mu \mathrm{l})$ of phosphate-buffered saline (PBS: $140 \mathrm{mM} \mathrm{NaCl}, 27 \mathrm{mM} \mathrm{KCl}, 8 \mathrm{mM}$ $\mathrm{Na}_{2} \mathrm{HPO}_{4}$, and $1.5 \mathrm{mM} \mathrm{KH} \mathrm{PO}_{4}, \mathrm{pH}$ 7.4) was used as a control. The plates with recombinant $B$. ignitus apidaecin active domain were incubated at $30^{\circ} \mathrm{C}$ (Gram-negative bacteria) or $37^{\circ} \mathrm{C}$ (Gram-positive bacteria) for $18 \mathrm{hr}$, and the resulting activity was determined by measuring zones of inhibition. In addition, the antibacterial activity of the recombinant $B$. ignitus apidaecin active domain was monitored using a liquid growth inhibition assay. A total of $200 \mu \mathrm{l}$ of the adjusted inoculum $\left(1.5-2.0 \times 10^{5} \mathrm{cfu} / \mathrm{ml}\right)$ was added to each well of a 96-well plate containing serial dilutions of recombinant $B$. ignitus apidaecin active domain, and the same volume of PBS was, again, used as a control. LB broth was used as the bacterial culture medium used in this study. The 96-well plates were incubated at $30^{\circ} \mathrm{C}$ (Gram-negative bacteria) or $37^{\circ} \mathrm{C}$ (Grampositive bacteria) for $18 \mathrm{hr}$ with shaking at $230 \mathrm{rpm}$. The inhibition of bacterial growth was determined by measuring the absorbance at $560 \mathrm{~nm}$. The growth inhibition results are expressed as the mean value of three independent replicates. The minimal inhibitory concentration (MIC) for the antibacterial assay is expressed as the lowest concentration that causes $50 \%$ inhibition of bacterial growth.

\section{Results and Discussion}

\section{Expression of the recombinant $B$. ignitus apidaecin active domain}

To assess the expression of the $B$. ignitus apidaecin active domain, the $51 \mathrm{bp}$ active domain was PCR-amplified from $B$. ignites cDNA using a primer set designed from the B. ignitus apidaecin gene sequence (Choi et al., 2008). The resulting cDNA fragment was inserted into a baculovirus transfer vector (Fig. 1A) to generate a recombinant 
A
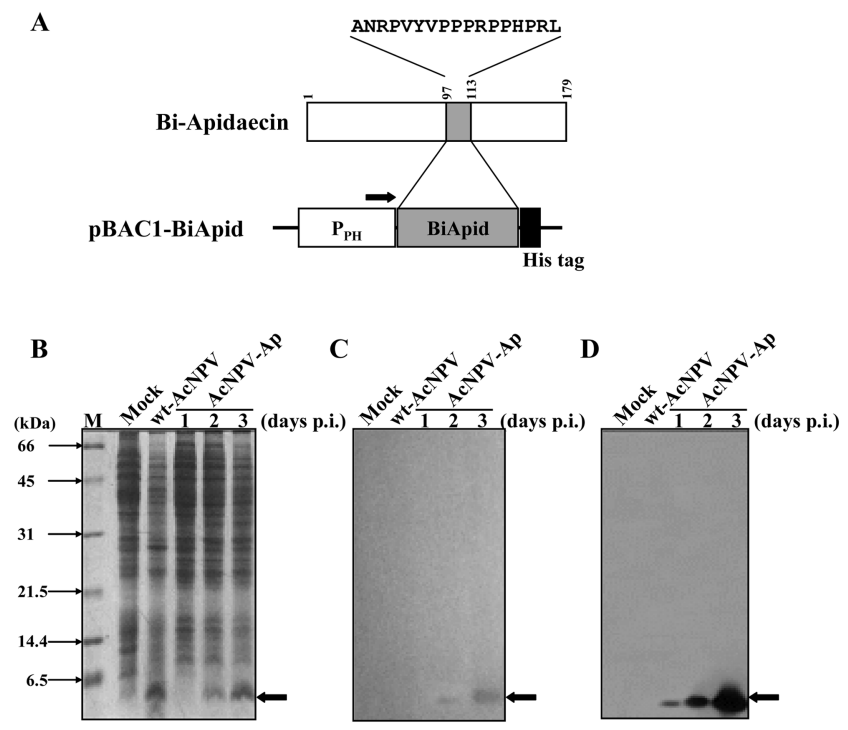

Fig. 1. Expression of the B. ignitus apidaecin active domain in baculovirus-infected insect cells. (A) The transfer vector pBAC1-BiApid for the production of recombinant AcNPV-Ap expressing the $B$. ignitus apidaecin active domain. The $B$. ignitus apidaecin active domain gene was placed under the control of the polyhedrin $\left(\mathrm{P}_{\mathrm{PH}}\right)$ promoter. The arrow indicates the direction of transcription. (B-D) SDS-PAGE and Western blot analysis of the recombinant $B$. ignitus apidaecin active domain. Sf9 cells were mock-infected or infected with either the wildtype AcNPV or the recombinant AcNPV-Ap at an MOI of 5 pfu per cell. The cells were collected at 1,2 , or 3 days postinfection (dpi). Total cellular lysates were subjected to $15 \%$ SDS-PAGE (B), electroblotted, and incubated with either antiB. ignitus apidaecin antibody (C) or anti-His-tag antibody (D). Molecular weight standards were used as size markers. The recombinant $B$. ignitus apidaecin active domain is indicated by arrows.

virus expressing the $B$. ignitus apidaecin active domain. A transfer vector (pBAC1-BiApid) was constructed by placing the $B$. ignitus apidaecin active domain cDNA under the control of an AcNPV polyhedrin promoter in pBAC1 (Fig. 1A). Recombinant AcNPV, which we have termed AcNPVAp, was produced in insect Sf9 cells by co-transfection with wild-type AcNPV DNA and the transfer vector.

The expression of the recombinant $B$. ignitus apidaecin active domain in Sf9 cells infected with the recombinant virus AcNPV-Ap was analyzed by SDS-PAGE (Fig. 1B). The recombinant $B$. ignitus apidaecin active domain was present as a single band of $2 \mathrm{kDa}$ in cells infected with the recombinant virus but not in cells infected with the wildtype AcNPV or mock-infected cells.

To characterize the expression of the recombinant $B$. ignitus apidaecin active domain in baculovirus-infected insect cells, the recombinant $B$. ignitus apidaecin active

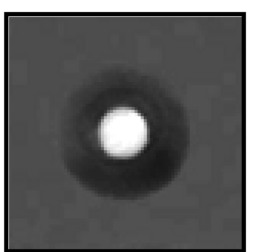

P. tolassi

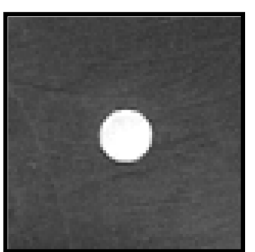

B. thuringiensis 656-3
Fig. 2. Antibacterial activity of the $B$. ignitus apidaecin active domain. The inhibition of bacterial growth by the B. ignitus apidaecin active domain is shown using the disc diffusion assay. The Gram-negative bacterium $P$. tolassi (left) and the Gram-positive bacterium B. thuringiensis 656-3 (right) are shown.

domain, with a molecular mass of $2 \mathrm{kDa}$, was purified from the recombinant baculovirus (AcNPV-Ap)-infected Sf9 cell culture supernatants using a HisTrap column. The purified recombinant $B$. ignitus apidaecin active domain was injected into mice to produce polyclonal antibodies. The expression of the recombinant $B$. ignitus apidaecin active domain in baculovirus-infected insect cells was confirmed by Western blot analysis using either antibodies targeting the recombinant $B$. ignitus apidaecin active domain (Fig. 1C) or the His-tag (Fig. 1D)

\section{Antibacterial activity of the recombinant $B$. ignitus apidaecin active domain}

The Gram-negative bacterium $P$. tolaasii causes brown blotch disease in A. bisporus and P. ostreatus (Jo et al., 2011). The apidaecins are highly active against Gramnegative bacteria (Casteels et al., 1989; Li et al., 2006). Therefore, it seems likely that the apidaecin from $B$. ignitus may have antibacterial activity against $P$. tolaasii. Thus, we evaluated the antimicrobial activity of the recombinant $B$. ignitus apidaecin active domain. Our findings demonstrate that the recombinant $B$. ignitus apidaecin active domain shows a bactericidal activity against $P$. tolaasii but lacks activity against $B$. thuringiensis (Fig. 2), which shows insecticidal activity against mushroom flies (Choi et al., 2004).

To determine if the bactericidal activity of the recombinant $B$. ignitus apidaecin active domain is more widespread, we assessed its antibacterial activities against Gram-negative and Gram-positive bacteria using a liquid growth assay. The result shows that the inhibitory effect of the recombinant $B$. ignitus apidaecin active domain on bacterial growth is exclusive to Gram-negative bacteria (Table 1 ), with activity against $E$. coli (MIC, $20 \mu \mathrm{M}), P$. tolaasii (MIC, $125 \mu \mathrm{M}$ ), and $P$. aeruginosa (MIC, $149 \mu \mathrm{M})$ and no activity against Gram-positive bacteria, even at the highest concentration $(300 \mu \mathrm{M})$ (Table 1$)$. 
Table 1. Antibacterial activity of the B. ignitus apidaecin active domain against Gram-negative and Gram-positive bacteria

\begin{tabular}{lc}
\hline \multicolumn{1}{c}{ Bacterial strain } & MIC $(\mu \mathrm{M})$ \\
\hline Gram-negative & 20 \\
E. coli & 125 \\
P. tolaasii & 149 \\
P. aeruginosa & \\
\hline Gram-positive & $\mathrm{ND}^{\mathrm{a}}$ \\
B. thuringiensis 565-3 & $\mathrm{ND}$ \\
B. megaterium & $\mathrm{ND}$ \\
B. subtilis & $\mathrm{ND}$ \\
B. cereus & \\
\hline
\end{tabular}

${ }^{\mathrm{a}}$ Not detected.

These results show that the B. ignitus apidaecin active domain is active against Gram-negative bacteria, including $P$. tolaasii.

In conclusion, these data demonstrate that the $B$. ignitus apidaecin is active against Gram-negative bacteria. The fact that the $B$. ignitus apidaecin active domain is active against $P$. tolaasii suggests that it is a potential antibacterial agent for the control of bacterial brown blotch diseases. Our study provides a basis for future studies focused on the development of bactericides for the control of bacterial pathogens in cultivated mushrooms.

\section{Acknowledgments}

This work was supported by a grant (204146-03) from the Ministry of Agriculture and Forestry, Republic of Korea.

\section{References}

Casteels P, Ampe C, Jacobs F, Vaeck M, Tempst P (1989) Apidaecins: antibacterial peptides from honeybees. EMBO J 8, 2387-2391.
Choi YS, Cho ES, Je YH, Roh JY, Chang JH, Li MS, Seo SJ, Sohn HD, Jin BR (2004) Isolation and characterization of a strain of Bacillus thuringiensis subsp. morrisoni PG-14 encoding ä-endotoxin Cry1Ac. Curr Microbiol 48, 47-50.

Choi YS, Choo YM, Lee KS, Yoon HJ, Kim I, Je YH, Sohn HD, Jin BR (2008) Cloning and expression profiling of four antibacterial peptide genes from the bumblebee Bombus ignitus. Comp Biochem Physiol B 150, 141-146.

Choo YM, Lee KS, Yoon HJ, Je YH, Lee SW, Sohn HD, Jin BR (2010) Molecular cloning and antimicrobial activity of bombolitin, a component of bumblebee Bombus ignitus venom. Comp Biochem Physiol B 156, 168-173.

Gill WM (1995) Bacterial disease of Agaricus mushrooms. Rep Tottori Mycol Inst 33, 34-55.

Je YH, Chang JH, Choi JY, Roh JY, Jin BR, O'Reilly DR, Kang SK (2001) A defective viral genome maintained in Escherichia coli for the generation of baculovirus expression vectors. Biotechnol Lett 23, 575-582.

Jo G, Hwang D, Lee S, Woo Y, Hyun J, Yong Y, Kang K, Kim DW, Lim Y (2011) In silico study of the ion channel formed by tolaasin I produced by Pseudomonas tolaasii. J Microbiol Biotechnol 21, 1097-1100.

Li WF, Ma GX, Zhou XX (2006) Apidaecin-type peptides: biodiversity, structure-function relationships and mode of action. Peptides 27, 2350-2359.

Paine SG (1919) Studies in bacteriosis II. A brown blotch disease of cultivated mushroom. Ann Appl Biol 5, 206-219.

Prashanth SN, Bianco G, Cataldi TRI, Iacobellis NS (2011) Acylhomoserine lactone production by bacteria associated with cultivated mushrooms. J Agric Food Chem 59, 11146111472.

Roh JY, Kim YS, Wang Y, Kiu Q, Tao X, Xu HG, Shim HJ, Choi JY, Lee KS, Jin BR, Je YH (2010) Expression of Bacillus thuringiensis mosquitocidal toxin in an antimicrobial Bacillus brevis strain. J Asia-Pac Entomol 13, 61-64. 